\title{
Study on the Urban Integration by Rural Minority Migrants in Xinjiang [1] -Taking Urumqi as an example
}

\author{
Zhibin Fu, Shaohua Yan \\ Shihezi University, Shihezi, Xinjiang Uyghur A. R., P. R. China \\ Party School of the XPCC, Wujiaqu, Xinjiang Uyghur A. R., P. R. China \\ 66478535@QQ.com, 575362389@QQ.com
}

\begin{abstract}
Keywords: Minorities; Rural migrants; Metropolises
\end{abstract}
\begin{abstract}
Accompanied with the rapid economic development, in Xinjiang, more and more rural minority migrants (abbr. "Migrants") moved to metropolises within the Autonomous Region. The Migrants, on one hand, provided great energies to the urban development, however, they became the main target by infiltrating the extreme religious ideology, brought negative impacts to the urban social stability. To solve this problem, the urban governments not only needed to strengthen their social comprehensive managing abilities, but also to provide kinds of social services, such as solving Migrants' living worries, improving official service capacities, promoting the "Family Culture" construction in Communities, in order to facilitate urban daily living, contacting and mingling between Migrants and natives, changing Migrants' traditional employment ideas, and improving their employment abilities.

With the development of the market economy to a broader and deeper dimension, the trans-regional flow of the Migrants in Xinjiang area is frequent. On the one hand, the trans-regional flow of the Migrants on has promoted the economic development of Xinjiang and ethnic communication. On the other hand, the Migrants have become the main target groups of the religious extremist ideology. According to the fact that $80 \%$ of Criminals during the "7.5" event are Migrants, and they involved a series of violent terrorist cases. It proves that the urban integration of the Migrants is the focus of the urban management in Xinjiang, which is directly related to the social stability of the city. It helps to bridge the gap between the people of all ethnic groups and the sense of distrust, and promote national unity and consolidate the unity of the Chinese nation, and promote the people of all ethnic groups to identify with the Chinese nation, at the same time, promoting social stability and long-term stability in Xinjiang.
\end{abstract}

\section{The Status Quo of the Migrants in Xinjiang Metropolises}

At present, the imbalance of regional development, urban and rural development imbalances still prominent in Xinjiang, especially in the four prefectures in Southern District into poverty population is large. In the first half of 2015, the national urban and rural residents' disposable income was 2.83 times, the Xinjiang urban and rural residents' disposable income was 9.24 times [2]. Second and third industrial development lags behind in Southern rural area, unable to provide more jobs, resulting in a large number of surplus labor transfers to the city. The Migrants affected by work skills, employment ability, cultural knowledge, language, customs, religious beliefs and other reasons, it is disadvantage in market competition for jobs in the city, the income is generally low, become a considerable part of city vulnerable groups.

Population Is Large. At present, Urumqi have about 30-40 million floating population living in Urumqi, and this figure is still increasing [3]. In the Tangshan District of Urumqi, the resident population of a minority nationality is about 230 thousand people, and the floating population of the minority nationality is about 120 thousand. A large minority floating population provides a continuously labor force to the city's development, increase the vitality of the city, on the other hand, Due to the influx of the city's population quality parameters, also become the potential factors affecting social stability in the city. 
Relative Concentration of Residence. Because of the influence of language, customs, religion, and restriction of economic income, minority floating population in Urumqi City mainly living in Yamarlik mountain, Heijia mountain, Da Wan and Yan'an road and Tuanjie Road, which is relatively concentrated and low rent areas, government management mechanism have Yamarlik mountain administrative committee, Heijia mountain administrative committee, Da Wan administrative committee and Yan'an Road administrative committee and Tuanjie Road office. According to statistics, the floating population and the minority people of the Ming Hua Street in Tianshan District have accounted for $80 \%$ of the total population.

Living with the common religious belief will undoubtedly strengthen the ethnic consciousness, at the same time, On the one hand, the function of the group identity of religion makes the ethnic members have strong cohesion, on the other hand will be members of the groups showed some resistance and rejection, for a multi-ethnic, multi-religious City, it is not conducive to inter-ethnic communication and interaction of integration, it is not conducive to the development of the construction of the embedded residential pattern of all ethnic groups, it is not conducive to the Migrants into the city as soon as possible, At the same time, it provides the convenience for the spread of extremist ideology in the Migrants.

Low Income, Poor Living Environment. In Urumqi, Migrants living in Yamarlik mountain, Heijia mountain, Dawan, Yan'an Road, Tuanjie Road area, which is basically in the combination of urban and rural areas of south of Urumqi, it becomes a relatively concentrated area of the Uygur nationality. These people who are mostly from southern rural or small town into the city of Urumqi Uygur have no fixed occupation, mainly engaged in the work of the low technological content, low income.

The living environment of floating population in the region is usually bad, such as Yamarlik inhabited areas is mainly private building built by the mountain, part of the floating population rented a cheap basement, and it is damp, dark, low, small, almost no water circuit lights and other public facilities, garbage everywhere, in contrast to the modernization of the mountain downtown. Poor living environment, low income and the city's bustling scene form a huge contrast, some of the minority will inevitably have a huge psychological gap, and even have the discontent with the government.

\section{Problems in the Migrants}

Aristotle said: people come to the city is to live; people live in the city, in order to live better. However, the Migrants in city have some problems, such as the general low cultural quality, the lack of legal consciousness and the lack of employment skills and so on; most of them live in bottom of the city. It provides a favorable space for the spread of religious extremist ideas. The spread of religious extremist ideas in the Migrants live in the urban fringe, not only cause the Migrants in the city rising rate of ordinary criminal offenses, also have the bad influence on social security, more easily lead to extreme ideology to confuse and terrorist violence, affect social stability.

The Migrants Is The Focus of the Infiltration of Religious Extremist Ideology. Due to the low cultural level, the lack of employment skills and other reasons, the income of the Migrants in the minority areas of Urumqi is generally low. In addition, grew up in the city in second and even third generation of the Migrants, the overall income is low, facing the gap between the rich and the poor in the city, their anti-social sentiment is strong, often easy to blame the life of poverty, the spirit of the depression, Social injustice phenomenon on ethnic and religious problems, easily incitement and confused by the "three forces". The criminals arrested in the "7.5" event in Urumqi who are outside the household population accounted for $80 \%$, the criminals under the age of 30 accounted for $89.2 \%$, the youngest only 11 years old [4]. At present, the Migrants inhabited areas lack basic cultural and recreational facilities, the lack of or even no legitimate religious sites, the needs of normal cultural entertainment and religious demand is difficult to satisfied, which will leave the space for illegal religious activities, the "three forces" for Uygur women's so-called 
"mother action " that is also called "Dawa mission", for the Uighur intellectuals" "Al-Zabut"and for the Uighur adolescents' "Al-Jihad" separatist activities are rampant ${ }^{[5]}$.

Urban Common Criminal Crime Rate Rises Affected by Religious Extremist Ideology. According to statistics from Xinjiang public security organs, over the total incidence of criminal cases $40 \%, 60 \%$ cases of public security for the Migrants crime. Especially in the area of concentration of some Migrants, the illegal crime rate of Migrants is as high as $70 \%$ or more ${ }^{[6]}$. The reason why there is such a high crime rate, in addition to the management of the government's functions is not good cause some of the Migrants is free from the effective management, mainly related to the quality of the Migrants and the high mobility. The high crime rate of Migrants has become the hidden trouble of social order and social stability. In some areas of Urumqi, the problem of theft of the Migrants of some ethnic minorities is prominent, which seriously affects the safety of the public's property. The deterioration of social order not only affects people's sense of security, but also the sustainable development of the city. In the interview, a number of people including office worker said that the number of Migrants has brought some negative effects and social pressure, and the social order in a few areas has also deteriorated.

Violent Terrorist Cases are Rising Because Deluded by Extremist Ideology. The "three forces" as a threat to social stability and security of Xinjiang's main destructive force, they constantly changing the way in the process of spreading religious extremist ideology, the process of national separation, different people have to face with different adjust strategically, they see the Migrants as an important development object to use to achieve their political plots. According to the relevant statistical data of public security organs, the problem of Migrants is related to the terrorist violence. According to the Xinjiang public security organs statistics, it was uncovered in 'three forces' violent terrorist cases in more than $90 \%$ of the gang members were arrested outside the residence in recent years. Especially in 2008, the main suspects of " 8.4 " and " 8.10 " violent terrorist case have been organized and developed in other place, and then fled back to the local crime. $80 \%$ criminals involved in the 2009 ' $7.5^{\prime}$ ' event is the Migrants or social idlers ${ }^{[7]}$. Criminal suspects detained by criminal detention after the " 7.5 " event, most of them are Migrants who are from south of Xinjiang come to Urumqi. The Migrants affected by the extreme ideology has embarked on the road of endangering the society, and the violent terrorist activities have been carried out under the planning and organization of extremist organizations.

\section{To Integrate Into the City as the Goal, to do the Service Management of the Migrants}

As Migrants, the discomfort and difficulties they have experienced in the city have undoubtedly caused great pressure and pain on their body and mind. Therefore, urban Migrants into the city, in addition to the proper management of Migrants, more important is to do a good job such as housing, medical care, employment, schooling and other aspects of the service work.

To Solve the Problem of the Migrants in the System. Migrants due to the household registration and other reasons, there are different degrees of difficulty in health care, child education, to apply for low-cost housing and other aspects, plus some of the minority floating population family, the income is generally low, and the difficulties encountered are far greater than the ordinary city residents. As a result, the government needs to increase the input of basic education funds in areas inhabited by the Migrants in the Migrants. Strengthen the registration of the Migrants, low-cost rental housing on the basis of the annual calculation points to apply for low rent housing. Medical treatment can increase the investment of community street medical institutions, ensure minor illnesses within the community, serious illness by the community contact referral for medical treatment. Medical reimbursement need to build a system, which is pay in advance by the places for medical treatment of Migrants , and then by the hospital to the relevant departments of the hospital and the Migrants of the local social security agencies unified settlement. Only by solving the worries of Migrants, they are able to exert their talents more fully in the city, and make greater contribution to the stability and development of the city.

Strengthen Management, Improve Community Service Capacity. Strengthen the management of Migrants' service, need to take measures to both management and service. Such as 
the Tianshan District of Urumqi Ming Wah Street police station and the region management committee to implement a "unitization, grid-enable, responsibility, digital" management, management efficiency and the ability of social security prevention and control are greatly improved, since 2015, the number of alarm decreased by $24 \%$, the incidence of criminal case decreased $38 \%[8]$. On the basis of the realization of high level management, it is more important to improve the service concept, service ability and service level. A community street worker to do service work, the first is to establish the concept of service. Community street as the government's most grass-roots management institutions, these institutions are often in contact with the Migrants, the advantages and disadvantages of the basic service directly affect the evaluation of the Migrants to the city and the government, the party and the identification of the party and the state. Promote the people oriented service and management idea to improve the quality of work at the same time, and strive to improve the satisfaction of the masses. In addition, to do a good job service of Migrants, community service personnel should have a certain understanding of the relevant national customs and religious practices, with the ability of minority language, in order to facilitate the work, grasp one hand information in time.

Promote the Construction of "Family Culture" in the Community, and Promote the Exchange of the Migrants and Natives. From July 2013 to September, the research group conducted a survey on the national unity education in Aqtu, Kuqa, Lop Nor, Khorgus and other places, including 373 questionnaires were completed by the Uygur nationality, including the "are you willing to answer and other national communication data as shown in the table 1

Table 1 National communication questionnaire:

\begin{tabular}{c|c|c|c|c|c|c}
\hline \multicolumn{2}{c|}{} & $\begin{array}{c}\text { Like, I often } \\
\text { communicate with } \\
\text { friends of other } \\
\text { nationalities. }\end{array}$ & Very eager & Dislikee & $\begin{array}{c}\text { Let nature } \\
\text { take its } \\
\text { course }\end{array}$ & Total \\
\hline \multirow{2}{*}{ Gender } & male & 139 & 29 & 11 & 3 & 182 \\
\cline { 2 - 7 } & female & 119 & 49 & 20 & 3 & 191 \\
\hline \multicolumn{2}{l}{ Total } & 258 & 78 & 31 & 6 & 373 \\
\hline
\end{tabular}

Data show that the minority people like or very eager to communicate with other ethnic groups to exchange the intention to account for $90.08 \%$, "do not like" contacts accounted for $8.31 \%$. The survey results show that the minority people have a very positive attitude towards the interaction with other ethnic groups including the Han nationality. Therefore, the street community should create conditions to promote the exchange between the Migrants and Natives, enhance mutual understanding. Women's federations at all levels, trade unions should play their own expertise, work with other Han people in the street community to establish a working relationship and communication relations, friendly relations and mutual assistance and cooperation, promote exchanges between the people of all ethnic groups. Hold the minority and Han nationality family mutual aid activities, minorities and the Han family hand in hand activities. Through these activities, to guide Natives and Migrants in the exchanges and mutual understanding and mutual respect, mutual tolerance, mutual appreciation, mutual learning, mutual help, let the sense of belonging and identity of the Migrants has gradually produced to the community street.

The Migrants to leave their homeland into the city, with blood and family based help each other life gone forever, in this case people lost the original feeling of belonging and sustenance, the pressure of city life has distorted the way of communication between people. The construction of community "family culture" can replace the original family home in some extent, it is the cultural activities as a link, "family culture" construction as the core elements, and Community Street built similar to the village unit, the community street is condensed into an organic resident mental unit. 
Community is the second home of the residents, the community is mutual help trusted center of life, and not merely a temporary residence.

Enhancing the Employment Ability of Migrants, and Promoting the Change of Employment Mentality. Employment is the basic of the urban survival of the Migrants. Urumqi's Migrants is generally engaged in the work, which is not a technical content work; most of them face the problem of low income and high labor intensity. It is not conducive to its long-term development in the city. Survey data showed that the average annual income of the Uighur population 3350 yuan, which is 3.4 times the income of the local people. The Migrants is engaged in the stalls and shops and doing odd jobs in the employment population accounted for $72.7 \%$, while employees are more stable accounted for only 7.4\% [9]. Therefore, it should be paid more attention to the professional skill education of young people, and it is the key link to realize the transformation from the primary labor force to the human resources. The content of vocational skills education should have the characteristic of practicability and wide employment. Also can use the way of order form training, directly to sign the contract with the employer, realize the study and the employment seamless connection.

Affected by the bad customs, some minority floating population in the work performance of lazy, procrastination, no sense of time, sense of discipline, resulting in some employers are reluctant to hire minority employment. In view of this, it is necessary to improve their behavior through publicity and education and other ways to change their attitude towards work. In addition, choice the typical of urban employment and entrepreneurship in the Migrants, and organize them to make a lecture tour., let them speak to more people to change the concept of employment, leading more and more Migrants employment and entrepreneurship.

Do A Good Job of the Docking of the Outflow and Inflow of the Migrants. General Secretary $\mathrm{Xi}$ Jinping put forward to the management of the Migrants two docking problem at the central national work conference. With the rapid development of Xinjiang economy and urbanization, Xinjiang township government should try to establish a cross regional cooperation mechanism with the main inflow place of Migrants, construction of the outflow place and inflow place of information exchange, personnel interaction, complementary and mutual cohesion work pattern, to carry out publicity and education, to promote economic and trade cooperation and common to maintain social stability, to encourage and support the masses of ethnic minority migrant entrepreneurship, employment .To establish and improve the information system of the Migrants, to build a big data platform, through focusing on the mining of Migrants' basic structure, source distribution, age and other information data,, improve the efficiency of data utilization at all levels of government and national affairs management and public management, to collect and update in time, strengthen the data analysis and information sharing. To do all kinds of contradictions and disputes, proper disposal of emergencies related to ethnic factors, when necessary to send personnel to participate in the disposal of the work flow, prevent the situation spread. To strengthen the legal publicity and education of the minority migrants, enhance their awareness of the laws and regulations, urban management rules and regulations.

\section{References}

[1] This is the National Social Science Fund Project, and it is the periodical results of "study on the positive role of stable Western religious figures and religious believers to the development of Xinjiang" (2011, Project approval number: No. 11XZJ020) and "the new urbanization process of Xinjiang religious change research" (2014, Project approval number: project approval number: 14xzj019) .

[2] "The first half of the Xinjiang economic development highlights", "Xinjiang Economic Daily", July 18, 2015. (In Chinese)

[3] Y.Zhang: "study on employment of Minority Floating Population in Urumqi city", "Journal of Urumqi municipal Party School of the Communist Party of China",( 2014)No.2. (In Chinese) 
[4] H.C. Wang et al. The theory and practice of ethnic religion under the new situation, the Central Party School Publishing House, 2013. (In Chinese)

[5] P.Xu: "7.5 events and the floating population of the Uygur nationality", "Eheoretical Trends", 2010. (In Chinese)

$[6,7] \quad$ H.B.Song et al. "The Service and Management of Floating Population in Xinjiang under theBackground of Anti-Terrorism", Journal of Xinjiang University (PHILOSOPHY, HUMANITIES AND SOCIAL SCIENCES EDITION), (2011) No.3. (In Chinese)

[8] "Meng Jianzhu in Xinjiang Research Stressed that the Innovation of Social Governance to Strengthen the Basic Level of Social Harmony and Stability of the People's Happiness and Peace to make a New Contribution", http://news.ifeng.com/a/20151214/46657280_0.shtml. (In Chinese)

[9] P.Xu, in the long river: "Urumqi Uighur Floating Population Social Exclusion and Integration", "Journal of South-Central University For Nationalities (PHILOSOPHY AND SOCIAL SCIENCES EDITION), (2011)No.6. (In Chinese) 